\title{
The Prisoner's Dilemma: An Adequate Concept for Ethical Analysis in Healthcare? A Systematic Search and Critical Review
}

\author{
Wolf Rogowski ${ }^{1}$ (I) Oliver Lange ${ }^{1}$
}

Received: 24 January 2020 / Accepted: 30 September 2020 / Published online: 5 November 2020

(c) The Author(s) 2020

\begin{abstract}
Schools of economic ethics inspired by Buchanan propose viewing ethical conflicts as prisoners' dilemmas (PDs) to facilitate solutions based on Pareto-improving institutional changes. Given that healthcare is determined by complex institutional arrangements, it has been claimed that this approach is also suitable for business ethics in healthcare. To scrutinize this claim, this research systematically searched for studies reporting PD structures in healthcare. PubMed, EconLit, and EconBiz were searched to find articles in German and English. Study type, characteristics of the game, and the proposed means to overcome the dilemma (if mentioned) were extracted and analyzed for aspects supporting or challenging the claim. Across 53 studies, 68 descriptions of various dilemmas in healthcare and public health were identified. Many authors successfully developed proposals for institutional change to overcome these dilemmas. However, many of these analyses exhibited limitations such as oversimplifications or inconsistencies. Also, the quality of evidence on both the characteristics of dilemmas and the effectiveness of proposed solutions was very poor. The subsamples of studies that explicitly cited the ethical approach were disjunct from those that applied empirical methods to analyze the dilemmas (frequently applying empirically richer frameworks than rational choice only). The large number of identified PDs indicates that economic ethics is relevant to healthcare. However, there is a need for further evidence to substantiate both the descriptive and prescriptive claims of this ethical theory. It should thus be seen as a complement that needs justification, rather than a substitute superior to other ethical frameworks.
\end{abstract}

Keywords Prisoner's dilemma $\cdot$ Healthcare $\cdot$ Systematic review

\section{Introduction}

Healthcare has been claimed to be incompatible with the homo oeconomicus model. According to the Central Ethics Committee of the German Medical Association, economic considerations are ethically appropriate if they assist medical professionals in pursuing their aim of parsimonious care for patients. However, if considerations of healthcare business profitability replace medical considerations about best patient care, this is an example of economization. Economization in healthcare is influenced by recent developments such as specialization, diffusion of high technology,

Wolf Rogowski

rogowski@uni-bremen.de

Oliver Lange

olange@uni-bremen.de

1 Department of Health Care Management, Institute of Public Health and Nursing Research, Health Sciences, University of Bremen, Bremen, Germany tendencies of concentration and privatization and increasing competitive pressure. It raises major ethical concerns, for example, because physicians and patients are not equally strong partners in the sense of a symmetric relationship of supply and demand. Instead, patients seeking healthcare are in a highly vulnerable position. Physicians, therefore, face a specific responsibility to act for the health benefit of their patients. This responsibility should guide the individual ethics of physicians and should be backed by the healthcare structures. Medical ethos should thus set limits on the economization of medicine and guide physicians' practice in the face of resource scarcity (Bundesärztekammer 2013).

Consider, for example, a self-employed cardiologist who increases his/her profits by administering percutaneous coronary interventions (PCI) in low-risk patients-a frequent problem in healthcare that exposes patients to unnecessary health risks and costs (Behnke et al. 2013). From the ethical perspective that connects the moral evaluation of actions or their consequences with the moral evaluation of the actor's intentions, it is straightforward to blame the cardiologist for 
his/her economized treatment practices. Apparently, there exists a tradeoff between the ethical goal of treating patients appropriately and the individual goal of maximizing profits. Business competition among cardiologists intensifies the problem as each cardiologist might anticipate that unless s/ he conducts the PCI, a competitor could do so. From this viewpoint, it seems obvious to call for limiting market competition in healthcare and to promote the traditional virtues of the medical profession.

Yet are considerations of business profitability actually problematic in healthcare? Is there truly a need for medical ethos, a system of rules for physicians which is based on traditional virtue ethics (Francis 2001) to contain this presumed economization? Should it be contained by restricting markets (e.g., situations where suppliers of healthcare services compete for patients) in healthcare?

From an institutional ethics view (Lutge et al. 2016) termed the prisoner's dilemma (PD) perspective here, the opposite could be claimed: profit maximization in a competitive market environment is seen not only, empirically, as a constituting element of modern societies but also, normatively, as the major social innovation that provoked the technological and economic evolution from which modern healthcare emanated. From this viewpoint, the recent developments identified by the Bundesärztekammer should be seen as indicators of unavoidable (and desirable) modernization of healthcare-increasing productivity of health service provision involves competition of highly specialized actors in increasingly complex health service provision processes. In such an environment, transactions become increasingly anonymous and traditional medical virtues tend to lose their orientation power for providing high-quality care at low costs. Given that business profitability has been an effective means to fill this gap, there is insufficient, rather than excessive, consideration of business profitability in healthcare. Greater knowledge should be acquired about the role of competition in healthcare and about how institutions can guide the activities of self-interested, competing players toward achieving socially desirable goals (cf. Lütge and Mukerji 2016).

The PD perspective is a leading theoretical approach in German business and economic ethics debates (Pies and Homann 2008), and has recently undergone further theoretical development (Lütge and Mukerji 2016; Pies 2009). It has been applied to various problems such as corporate social responsibility (Sacconi 2006, 2007), business ethics more generally (Lutge et al. 2016), and the design of the German social market economy (Martino 2018). The PD perspective is also claimed to be a valuable approach for ethics in healthcare (Knoepffler and O'Malley 2016). This paper aims to scrutinize this claim.

The manuscript proceeds as follows. In the next section, we present the PD perspective's background assumptions, central concept, ethical basis, and practical use in applied business ethics. We also present three claims it involves that (1) markets, (2) PD structures, and (3) new institutions to overcome them can all be identified in modern healthcare provision. To explore whether this is the case, we then conduct a systematic search and critical review of reported PDs in healthcare. In the third section, we present the search and review methods. The methods are orientated at current standards of practice in empirical bioethics research (Ives et al. 2018) and systematic review and meta-analyses (Liberati et al. 2009). The fourth section documents the search results including descriptions of dilemma structures and the role of market elements, the proposed means to overcome them, and the evidence on which the studies were based. While we identify a large number of reported PDs, these descriptions and proposals for overcoming the described dilemmas have remarkably limited evidential bases. In the fifth section, we discuss the relevance of the PD perspective for healthcare, presenting its limitations and further research needs. Briefly, the two main arguments will be as follows. First, although evidence about markets in healthcare is limited, this can easily be accounted for by detaching the PD perspective from claims about markets. Second, claims about the applicability of the PD perspective to healthcare should be conditioned on evidence that the problems display features of PDs and that the proposed institutions are effective for overcoming them. Because the PD perspective remains silent regarding moral problems that cannot be reframed as PDs, these other problems may be assumed away if the PD perspective is applied without these conditions. The final section then concludes.

\section{The Prisoner's Dilemma Perspective}

The PD perspective originates from a game-theoretic concept originally developed by Merrill Flood and Melvin Dresher at RAND Corporation and coined and formalized by Albert Tucker in 1950 (Poundstone 1992, p. 18). The PD inspired philosophers, economists, and researchers from multiple other disciplines and about 16,000 articles about it have appeared since 1960 (Peterson 2015, p. 64). One of them was James Buchanan and his fellow constitution economists who used the PD to develop a justification of institutions in modern constitutional democracies on the basis of individual utility maximization (e.g., Brennan and Buchanan 1985; Buchanan 1975). In the German business ethics literature, this work has been further developed as "interaction economics" by Homann and Suchanek (2005, p. 22), as "ordonomics" by Pies (2009), and as "order ethics" by Lütge (Lütge and Mukerji 2016; Lutge et al. 2016). 


\section{Background Assumptions}

It assumes that today's exchange of goods and services differs fundamentally from that of the premodern era, where economic interaction largely occurred among individuals within regionally and socially confined groups sharing a common morality. Under the conditions of modernity, economic exchange occurs within anonymous (world) markets among individuals holding highly heterogeneous moral views. Here, individual moral convictions no longer serve to facilitate successful exchange and a new ethical framework is necessary to analyze moral issues. The PD perspective provides such a framework. It rests on the assumption that successful interactions are the source of welfare in modern economies. However, their success is hampered by three characteristics they share. First, there are always both shared interests (the gains from productive cooperation) and conflicting interests (the attraction of deceiving the partner and benefiting from their efforts without performing one's own obligations). Second, the desired outcome cannot be achieved by one interaction partner on his/her own. Third, any advance effort toward the desired outcome can be exploited by the interacting party. Therefore, interactions can only be successful if institutions are in place that overcome the overt or latent PD structures and provide both interacting parties with stable expectations that the other partner will cooperate (Lutge 2005; Homann and Suchanek 2005, p. 369ff.).

\section{Prisoner's Dilemma}

The three characteristics can best be illustrated by the gametheoretic concept of the prisoner's dilemma (PD). Table 1 illustrates a dilemma between physicians $(\mathrm{P})$, who could cooperate (restrain their use of pooled resources provided by sickness funds) or defect (use resources excessively), and sickness funds (S), which could cooperate (grant unlimited access) or defect (limit access wherever possible).

Compared with situation (III) of maximum resource use by physicians and maximum ad hoc cost containment by sickness funds, the game-theoretic players $\mathrm{P}$ and $\mathrm{S}$ are better off in situation (I), where unlimited resources are provided to physicians who use the resources parsimoniously. However, both players have incentives to defect. Therefore, benefit maximization leads them both toward

Table 1 Dilemma structure

\begin{tabular}{|c|c|}
\hline & $\begin{array}{l}\text { Physicians (P): } \\
\text { Cooperate vs. Defect }\end{array}$ \\
\hline $\begin{array}{l}\text { Sickness funds (S): } \\
\text { Cooperate vs. Defect }\end{array}$ & $\begin{array}{ll}\text { (I) } \mathrm{P}: 2, \mathrm{~S}: 2 & \text { (II) } \mathrm{P}: 0, \mathrm{~S}: 3 \\
\text { (IV) } \mathrm{P}: 3, \mathrm{~S}: 0 & \text { (III) } \mathrm{P}: 1, \mathrm{~S}: 1\end{array}$ \\
\hline
\end{tabular}

Table 2 Resolved prisoner's dilemma

Physicians $(\mathrm{P})$ :

Cooperate vs. Defect

\begin{tabular}{lll}
\hline Sickness funds (S): & (I) P:2, S:2 & (II) P:0, S:3-x<2 \\
Cooperate vs. Defect & (IV) P:3-x<2, S:0 & (III) P:1, S:1 \\
\hline
\end{tabular}

situation (III), representing an equilibrium in dominant strategies toward a Pareto-inferior social state (Backhaus 2005, p. 233; Homann and Suchanek 2000, p. 37; Rogowski 2018).

In an anonymous healthcare system, even if a single physician may be prepared to act parsimoniously, s/he can anticipate that at least some of her/his colleagues are likely to defect. This can also be anticipated by the sickness funds, which will react accordingly. Rather than "playing fair" within the existing game, the proposed solution to a PD is to play a different game. This involves changing the payoff matrix, for example, by imposing some punishment to decrease the payoffs for defection by $x$, so that they are lower than the payoffs in quadrant (I). Table 2 illustrates this new situation.

The PD view applies this game-theoretic concept to situations that differ from the classical PD. Frequently, the two-sided, two persons dilemma is used as an illustration for an n-player PD. This is a situation involving at least three players; however, it is analogous to the PD with two strategies of cooperating and defecting and a Nash equilibrium in a Pareto-inferior social state. Different from the symmetric two-sided dilemmas illustrated above, one-sided PDs are characterized by an asymmetry between partners, with one strong partner who might deceive their weaker counterpart. Anticipating this risk, the latter refrains from cooperating. Consider the example of a new private health insurance fund $(\mathrm{F})$ in an economic environment characterized by fraud and corruption. Here, an individual (I) may refrain from cooperating (signing an insurance contract and paying monthly contributions) because s/he doubts that the fund will cooperate by meeting its payment obligations when a medical treatment is provided (see Fig. 1). For a rational individual to become willing to cooperate, the insurance fund would have to make a credible self-commitment that decreases the benefit of defection to an amount less than the benefit of cooperation (see Fig. 2) (Pies and Sardison 2006).

\section{Ethical Basis of the PD Perspective}

The PD perspective can be assigned a contractarian foundation (Lutge et al. 2016) that holds individuals to be "the unique unit of consciousness from which all evaluation begins" (Brennan and Buchanan 1985, p. 25f.): there are 


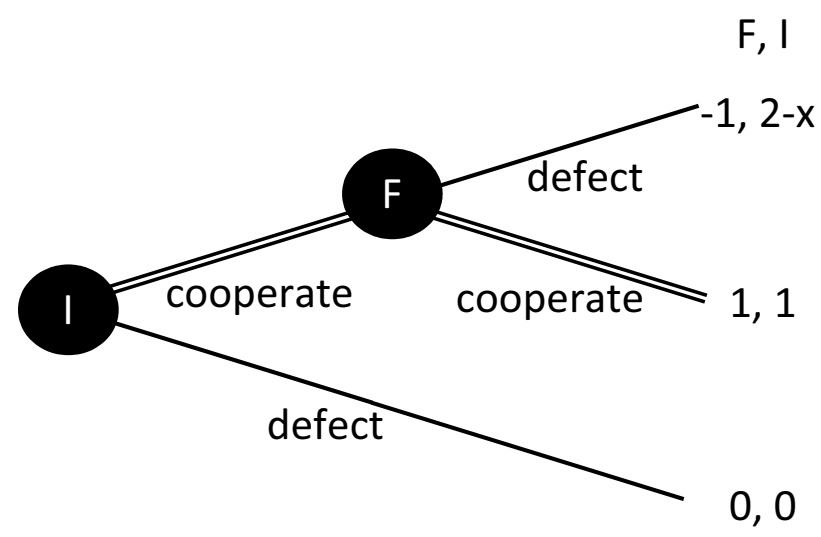

Fig. 1 One-sided PD with self-commitment

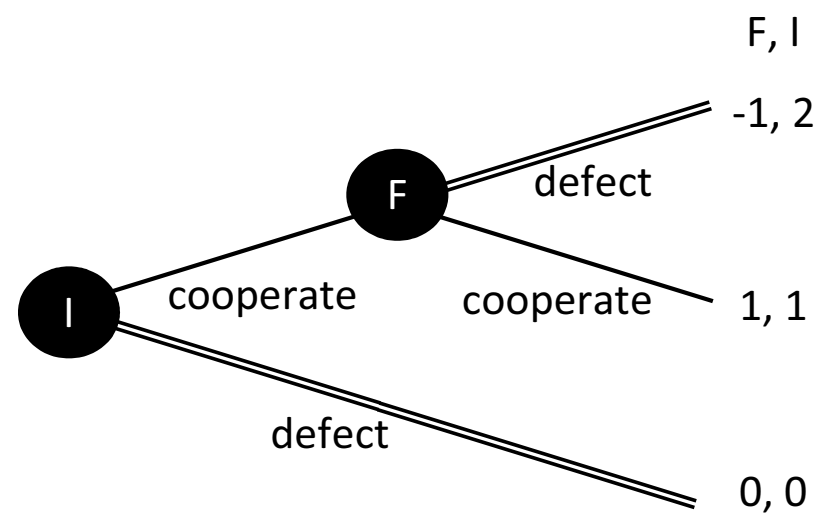

Fig. 2 One-sided prisoner's dilemma

no other sources of value (like natural rights or God) that could legitimize collective order. Following the contractarian ideal, individuals enter discussions and reach agreement about individual rights and obligations and the authority charged with enforcing them. All individuals are seen as moral equivalents, so there is no reason to exclude anyone from this negotiation process - the normative basis of a rule is, thus, unanimous consent from those covered by the rule (who consent because it is to their advantage). Brennan and Buchanan note a number of counter-arguments to their position. For example, the sets of rules observed today emerged historically in a manner that frequently deviated from such an ideal decision process. However, they claim that for normative evaluation, the relevant question is whether rules might conceptually have emerged from such a voluntary agreement, rather than how they emerged historically; the conceptual question also provides an important point of reference for constructive constitutional reform. The observation that decision rules in political practice frequently deviate from unanimity is not seen to challenge the normative principle of unanimity. For practical reasons, there might be consent to deviate from the decision rule for less important matters (Brennan and Buchanan 1985, p. 23ff.).

Lütge et al. demonstrated that the contractarian framework for constitutional reform is also relevant for business ethics: interaction in modern economies abounds with incomplete contracts (e.g., regarding employment, long-term cooperation, and insurance). Honest partners who fulfill their parts of the contract bear the risk of the other partner capitalizing on gaps in the contract, interpreting ambiguous sections to their advantage, or failing to perform a service in a situation where enforcement is too expensive. Despite potentially high gains from cooperation, risk-averse, rational actors may not enter into such contracts. Therefore, businesses have incentives to invest in enforceable rules that help to overcome this uncertainty. One example of such investment is corporate social responsibility (Lutge 2005; Lutge et al. 2016).

Knöpffler et al. claim that the most prominent traditional approaches to medical ethics share the limitation of omitting incentives from their analyses, and instead focus on ethical considerations at the level of individuals and their interactions. As the PD perspective overcomes this limitation, it may be a valuable approach for ethics in the healthcare sector (Knoepffler and O'Malley 2016).

\section{Use of the PD Perspective in Applied Business Ethics}

Authors following the PD perspective aim to integrate the practical question of how to implement solutions to moral concerns into the ethical analysis (Pies and Sardison 2006). They reject calling for more individual morality, claiming that morally "well-motivated" individuals are often systematically prevented from acting upon this motivation. Moral problems are seen as unintended consequences of a reasonable fear of exploitation by others under the existing incentive structure. Therefore, the PD perspective proposes redirecting focus from the actions or motivations of actors onto the institutions and rules. Guided by the PD, the moral problems of economic interaction are reframed as unintended collective self-damage. It is assumed that rather than tradeoffs between ethical aims and self-interest, the moral problems are, in fact, forgone win-win solutions. The identification of these potential Pareto-improvements and the development of rules facilitating their realization entails aligning ethical aims with self-interest, rather than emphasizing ethics over self-interest. The PD perspective provides a framework to guide this process (Lutge et al. 2016; Pies 2009).

Scholars in this tradition frequently contend that the spontaneous order emerging from market competition is the default case of productive social interaction: guided by an appropriate structure of rules, individuals who follow their own interests also further the interests of others by contributing to a network of societal collaboration that cannot 
be fully understood by the individual contributor and does not require extraordinary morality of individuals (Brennan and Buchanan 1985, p. xvi). To analyze ethical conflicts in market competition, three levels of "rule following," "rule setting," and "rule finding" can be distinguished (Pies 2011). If market interactions (rule following) involve ethical challenges, these should be analyzed as PDs and the regulatory framework should be modified in a manner that renders individual profit maximization also socially beneficial (rule setting). Where the situation is not yet perceived as a PD or rules have not yet been established, social discourse is needed to develop a Pareto-improving modification of the regulatory framework (rule finding). Rather than calls to embrace morality and reject markets, "enlightened selfinterest" within markets (Beckmann and Pies 2016) should assist in finding desirable common ethical goals, which may then be reached by institutions that resolve PDs.

\section{Three Claims the PD Perspective Involves}

Previous work on using the PD to analyze ethical topics has addressed various challenges such as the limited theory of rationality it involves or its limited account of communication and societal discourse (Peterson 2015). Also, more specifically, the PD perspective as an ethical approach has been challenged on various grounds (see e.g., the discussion statements accompanying the two essays Pies 2017; Homann and Pies 1994). This study is restricted to analyzing three claims it involves. First, by taking markets as one of the two "conditions of modernity" and, thus, the starting point of the analysis, the normatively relevant question of whether social collaboration should be organized by markets is excluded from normative analysis (Kettner 2017). In modern healthcare systems, (price-building) markets typically do not prevail and there is no consensus that this would be desirable. On the contrary, the recognition of market failures is among the key elements of health economic analysis (Arrow 1963). For the PD perspective to be applied to healthcare without further modification, it would, first, need to be established that market elements can indeed be identified in the structure of modern healthcare provision. Second, the gametheoretic framework could only be successfully applied under the non-trivial value-theoretic premise that all values addressed within the framework are fully commensurable (Kettner 2017). The conflicts would need to be sufficiently simple in structure that PD structures and a Pareto-superior combination of strategies could indeed be identified. Third, there would need to be potential for developing new institutions that are effective in overcoming these structures. This could best be established by evidence of effectiveness for these new institutions. In summary, the three claims are that (1) markets exist, (2) PD structures exist, and (3) new institutions exist that are effective in resolving the PD problems.
To what extent the three claims are met in healthcare is currently unknown. This study aims to address these issues from an empirical ethics perspective (de Vries and Gordijn 2009), using the methodology of systematic review, which is frequently applied in health sciences.

\section{Methods}

Contrary to widely held perceptions about medical ethics, the PD perspective claims that considerations of business profitability are not problematic in healthcare and refutes the need for individual ethics to contain such presumed economization. Instead, the PD perspective assumes that markets are the default patterns of exchange in modern economies; considerations of business profitability should be valued as they facilitate the effectiveness and efficiency of exchange. Where apparent conflicts between business profitability and other considerations of good healthcare appear, there is a need for institutional rather than individual ethics. Those affected by these problems should identify the underlying detrimental incentives and agree on institutional settings to overcome them.

This normative premise rests on the empirical assumptions that markets prevail, that constellations like the PD exist, and that institutions can be identified to overcome them. Empirically, this study therefore assesses to what extent PDs have been reported in the literature, together with evidence of the effectiveness of institutions to overcome them. In ethical terms, the study subsequently discusses the validity of the PD perspective's normative claims for healthcare.

The search aimed to identify studies that applied a PD perspective to healthcare and public health. To develop a search strategy, we employed a pearl-growing approach of multiple explorative searches of different databases (EconLit, PubMed), Google, and literature portals focusing on German literature (Wiso and EconBiz); we also used reference tracking, conducted hand searches of key academic scholars' reference lists, and sourced publications through personal contacts. After reaching saturation, we identified a broad search strategy combining indicators of the concepts "prisoner's dilemma" and "healthcare" in PubMed, EconLit, and the EconBiz data portal (which includes ECONIS, RePEc, EconStor, and other databases), which would have detected all studies identified in our earlier searches that transparently and plausibly describe PDs. A systematic search based on these terms was conducted on January 29 and 30, 2019 (details are available from the authors upon request).

Titles and abstracts of identified database entries were screened independently by two individuals listed in the "Acknowledgments" section (TG, HH, PP, and AZ). For a 
publication to be included in this study, all elements of a PD had to be clearly identified (players, strategies, Nash equilibrium in Pareto-inferior social state), or the publication's authors had to identify the situation as a PD and provide at least some information describing it using game-theoretic concepts. A publication was considered to have application to healthcare if the context of any type of healthcare setting could be identified, e.g., topics related to patient-physician interaction, hospital management, or reimbursement issues. Publications outside the healthcare sector were considered to have public health application if a direct link from the PD to health outcomes was identifiable. Publications in German and English language were included, and all publication types were eligible, e.g., essays that merely describe the authors' view, observational studies, randomized controlled trials using empirical methods to characterize PDs and means to overcome them, and simulation models quantifying the payoffs of single players.

As the EQUATOR Network has no standardized reporting guideline for applications of game theory in healthcare, we developed a specific data extraction form. To assess which dilemma structures were described, the following items were extracted from the studies: healthcare/public health topic addressed by the study, type of game, players, strategies, and payoffs or qualitatively described outcomes. To assess the evidence on which the study and the proposed solution was built, study type and means to overcome the dilemma (if mentioned) were also extracted.

The PD perspective assumes that markets are a key condition of modernity. To explore whether this was the case in the analyzed publications, we assessed whether each described dilemma occurred within a market interaction. "Market" was defined as a situation where suppliers and consumers of a (healthcare) product or service compete for successful exchange, with at least two suppliers or two consumers. As the existence of markets appeared to be a gradual rather than binary phenomenon, the publications were assigned to one of four degrees of "market competition," ranging from market competition as described in economic textbooks to a situation where no market competition could be identified at all. Specifically, the study distinguished between standard market competition (defined as competition between companies or consumers in a price-establishing market); managed competition (defined as competition among individuals or institutions such as physicians but in a highly regulated environment without prices established by supply and demand); elements of competition (defined as a situation in which the interaction could be clearly related to some kind of competition); and no competition (defined as a situation where no competition could be identified but a different problem was described).
The PD perspective also claims to be suitable for ethical analysis of anonymous interactions on a large scale, like those that typically occur in markets. To explore whether the identified publications addressed such large-scale anonymous interactions, the organizational level of analysis was extracted, distinguishing between macro, meso, and micro level. Macro-level studies met the criterion because the dilemma appeared to represent a typical conflict occurring frequently at the national or healthcare system level. Meso-level studies only partly met the criterion because the described dilemma appeared to represent a conflict confined to an organizational or local setting where individuals are likely to know each other, rather than acting anonymously. Finally, micro-level studies did not meet the criterion because they appeared to describe a specific, singular conflict among individuals.

Most of the items were extracted independently by the first author (WR) and one of the four individuals TG, $\mathrm{HH}$, $\mathrm{PP}$, and AZ. The healthcare/public health topics were structured and assigned to different categories by WR. The items "Institutional level" and "Type of market" were extracted independently by the two authors based on the data extracted above, and disagreements were resolved by consensus.

In addition, to assess the applicability of the PD perspective to healthcare, we extracted key strengths of the approach and aspects of each study consistent with its assumptions (thereby confirming its applicability), as well as key weaknesses and aspects inconsistent with a PD perspective of ethical conflict (thereby challenging its applicability). In the discussion section, the normative claim summarized above is challenged in light of the information extracted from the studies.

\section{Results}

\section{Literature Searches}

Figure 3 displays the study selection process. A total of 2435 studies were identified by the systematic search. After removing duplicates and screening titles and abstracts, 86 studies remained for full-text assessment. In total, the review identified 53 peer-reviewed articles, book chapters, and monographs reporting 68 descriptions of various types of dilemmas. Figure 3 presents the study selection process as a PRISMA flow chart (Moher et al. 2009). The full, agreed extraction table is available from the authors upon request.

\section{Topics Assessed as PDs}

The studies addressed a wide range of topics related to the provision and exchange of healthcare goods and services. 
Fig. 3 Study selection process as a PRISMA flow chart (Moher et al. 2009)

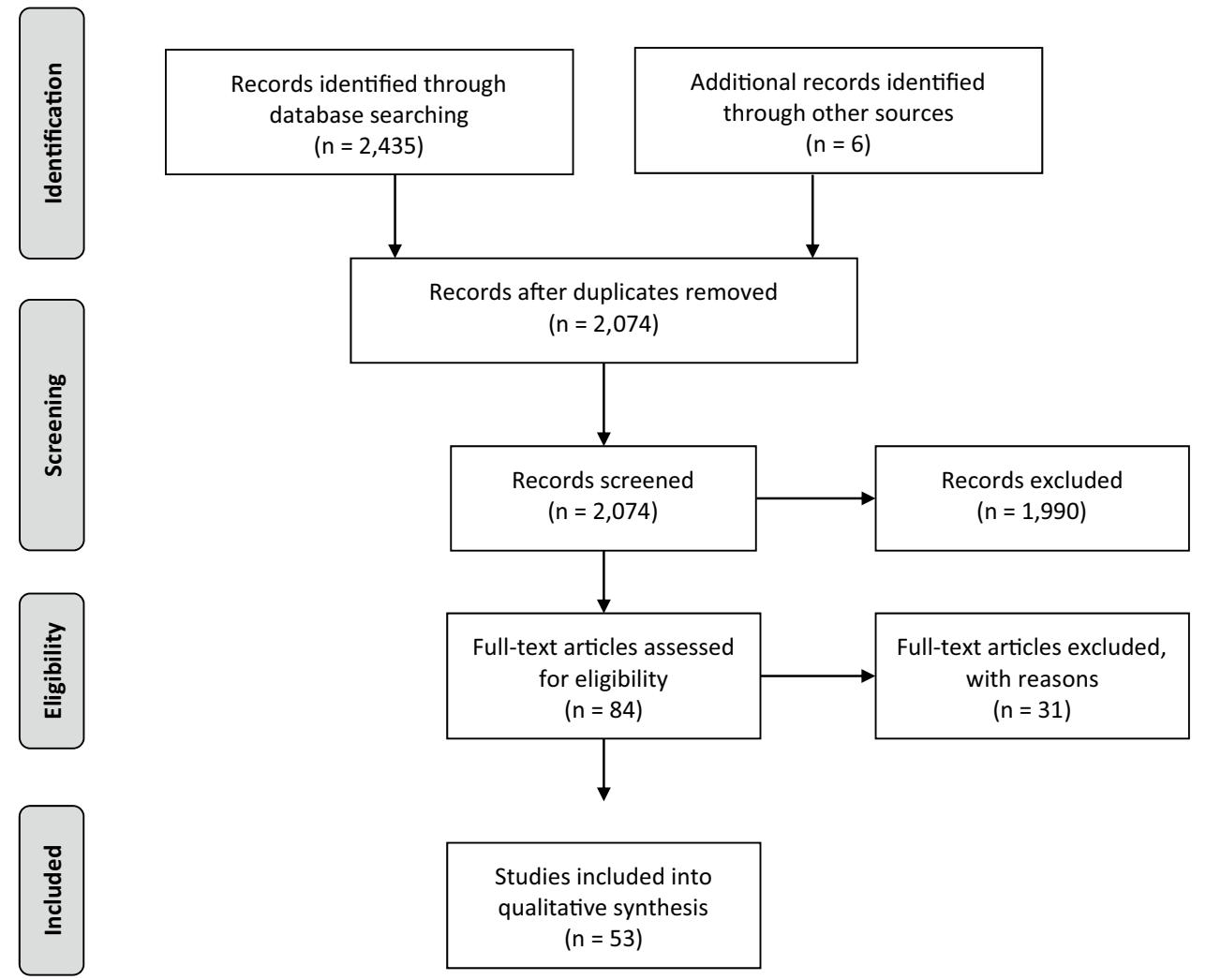

Eighteen studies addressed topics related to coverage policy. A main theme was overprovision of care: seven of the published dilemmas described different versions of the problem that public coverage can incentivize physicians and patients to overuse the pooled healthcare resources (Arrow 1963; Backhaus 2005; Balshem et al. 2011; Beckmann et al. 2004; Beckmann and Pies 2016; Behnke et al. 2013). A further seven analyses addressed the same or similar problems within the context of how to reform existing coverage and reimbursement systems (Behrend et al. 2007; Benjamini and Gafni 1986; Bennett et al. 1995; Berndt and Trusheim 2017). Typically, the PD perspective recommends regulation to overcome dilemma structures. Two of the identified analyses assessed the development of regulation as yet another dilemma (Balshem et al. 2011). Furthermore, two studies addressed the use of cost-effectiveness within coverage decisions (Bernstein 2000; Betsch 2014).

Fifteen studies addressed interactions between individuals within various healthcare or related processes and analyzed how these processes could be improved. Nine of these described dilemmas addressed interactions among physicians (Backhaus 2005; Balshem et al. 2011; Bhattacharyya and Bauch 2012; Böhm et al. 2016; Boos 2002; Brennan and Buchanan 1985; Brewer et al. 2017), including topics such as fair division of labor among colleagues, fairness in organ transplantation, avoiding erratic behavior during case conferences, and decreasing the inefficiently high number of applications for residencies. Six dilemmas assessed physician-patient interactions (Brouwer et al. 2008; Buchanan 1975; Bundesärztekammer 2013; Bungenstock 2011; Chambers 1995): examples include patients' trust in researchers in clinical trials or in the psychotherapist during analysis; commitment to appropriate diagnosis by the physician and patient compliance with the therapy; and interactions between a physician diagnosing brain death and parents hoping for recovery when deciding whether to disconnect a child from a respirator.

Another 14 dilemmas described conflicts within the management of healthcare organizations, rather than individual conflicts between physicians or between physicians and their patients (Creasy and Kinard 2013; Davis and McMaster 2015; Vries and Gordijn 2009; Djulbegovic and Hozo 2012; Djulbegovic et al. 2015; Dolan et al. 1999; Eber 2008; Ellingsen and Obstfelder 2007; Eussen et al. 2017; Feng et al. 2018; Francis 2001). Nine of these analyses addressed issues of hospital management such as whether or not to specialize (which would be societally, but not individually, efficient), whether or not to acquire technology or invest in marketing beyond the socially optimal level, and how to increase physicians' use of a new electronic booking system. Three studies addressed the management of private health insurance and health maintenance organizations, HMOs (Vries and Gordijn 2009; Djulbegovic et al. 2015; Francis 2001), e.g., contractual questions between physicians and HMOs. 
Two analyses were dedicated to pharmaceutical research and development management (Davis and McMaster 2015; Feng et al. 2018), such as the strategic choice when defining the cutoff threshold for companion diagnostics.

Problems related to specific public health topics were described in 21 of the dilemmas. These included addiction (Funk et al. 2010; Gansen et al. 2019; Gkika et al. 2018), doping (Glied 2001; Goodman 1998; Guyatt et al. 2008; Haugen 2004), public health issues in developing countries (Heckerling et al. 2006; Homann et al. 1994; Homann and Suchanek 2000, 2005; Ives et al. 2018; Liberati et al. 2009), safety issues (Jadlow 1978; Janssens and Kramer 2016), and vaccination (Kettner 2017; Knoepffler and O'Malley 2016; Kolan 1996; Krauth et al. 1997; Kuga et al. 2019). The most frequently addressed topics included incentives to take performance-enhancing drugs in sporting competitions despite any associated health risks, and incentives not to vaccinate despite the benefit of herd immunity.

Most of the descriptions of dilemmas appeared unrelated to the ethical approach of the PD perspective, which was only cited in 11 of the dilemmas (Arrow 1963; Backhaus 2005; Benjamini and Gafni 1986; Bennett et al. 1995; Betsch 2014; Gansen et al. 2019; Homann and Suchanek 2000).

\section{Descriptions of Dilemma Structures}

Typically, studies presenting the PD perspective use the two-sided PD for illustration; indeed, most of the dilemmas identified in this review (40) displayed this structure. A total of 24 structures described $n$-sided PDs; 5 structures were 1 -sided dilemmas. They involved different players, most frequently including physicians of different specialisms, patients or statutory health insurance professionals, healthcare funders, those working in healthcare organizations like hospitals, or the theoretical player "society."

The PD perspective is oriented toward analyzing ethical conflicts in the context of relatively anonymous social interventions; consistent with this, 56 of the dilemmas could best be assigned to the macro level of healthcare organization. Of the other dilemmas, nine occurred at the meso level of healthcare organizations, and only three were confined to the micro-level perspective of singular actors.

The PD perspective claims that markets are a basic condition of modern economies. Some form of managed competition (e.g., free choice for patients implying competition among service providers) was a major characteristic in 30 of the dilemmas; at least some elements of competition could be identified in a further 12 dilemmas. However, priceestablishing markets, the default frequently referred to by proponents of the PD perspective, occurred only in four of the dilemma structures. In 22 of the dilemmas, the situation could not be described as characterized by competition. For example, where individuals were deciding whether or not to vaccinate, the main feature appeared to be choice between different risk (and cost) profiles, rather than the market activities of healthcare providers competing for clients or healthcare consumers making bids to access a product they value higher than the price.

Furthermore, the categories used for describing and analyzing the dilemmas deviated slightly from the rational choice-oriented PD perspective, which incorporates the notion that to change behavior, the rational individual's payoffs must be modified. In some cases, the problem appeared to be that the perceived payoffs were contestable or clearly erroneous (Behnke et al. 2013; Janssens and Kramer 2016; Knoepffler and O'Malley 2016; Krauth et al. 1997), e.g., the overestimated harms and underestimated benefits of vaccination. More complex models of the vaccination dilemma included not only decision and disease characteristics in susceptible-infected-recovered-susceptible models but also awareness of the disease (Funk et al. 2010). In the description of the dilemmas and possible means to overcome them, some studies explicitly adopted concepts like the Risk, Attitudes, Norms, Abilities, and Self-regulation (RANAS) model of behavior change or factors from social dilemma theory (Homann and Suchanek 2005; Ives et al. 2018).

Not all dilemmas were correctly specified, for example, some had missing information, some confused strategies with chance events, and some had payoffs that were implausible or inconsistent with the assumed dilemma structure. Frequently, descriptions were accompanied by graphical representations analogous to the classical PD. It should be noted, however, that these descriptions were not always precise enough to provide details about every element of the game.

\section{Proposed Means of Overcoming the Dilemmas}

In 15 of the presented dilemmas, no means to overcome them were mentioned; instead, these studies were used to structure the problem and illustrate presumed determinants. In the others, the means to overcome the dilemmas were developed to various degrees; some studies offered vague proposals to modify incentives, while others presented more elaborate proposals of how the dilemmas could be resolved by new institutional arrangements.

Many of these proposals were consistent with the categories used by the PD perspective, they included binding contracts, rules, and penalties, such as the establishment of mandatory insurance and obligatory coverage rules to counter incentives to underfund and overexploit limited healthcare resources (see e.g., (Arrow 1963; Balshem et al. 2011; Betsch 2014)). Also, some proposals were developed to overcome specific problems. For example, different game-theoretic analyses were presented to address incentives to dope. Depending on key aspects modeled in 
the analysis, solutions included increasing the probability of being detected and the damage of exposure, and greater transparency about (legalized) doping (Glied 2001; Goodman 1998; Guyatt et al. 2008; Haugen 2004).

Some analyses presented solutions that were consistent with the PD perspective but seemed arbitrary, rather than having been derived from a thorough investigation of the topic. One example is a study developing a blueprint for market-oriented healthcare reform: from an ethical and economic perspective, this study would have benefited from incorporating the literature on market failures and equity issues in healthcare (Bennett et al. (1995)). It was also unclear in some studies whether the solution was derived from the analysis or whether the analysis was presented to substantiate the claim that the proposed solution should be followed. Example cases include a physician calling for reduced health policy regulation (Balshem et al. 2011) and a veterinarian advocating more collaboration with human healthcare physicians to fight zoonotic diseases within the proposed "one health approach" (Bhattacharyya and Bauch 2012).

Some solutions also deviated from what PD perspective proponents would advocate. For example, some authors proposed emphasizing a common goal and interests (Bhattacharyya and Bauch 2012), reducing fear of medico-legal consequences (Brennan and Buchanan 1985), or shifting actors' perception of the situation. In particular, they called for realizing that the dilemma is a repeated rather than a single interaction (e.g., (Vries and Gordijn 2009; Homann et al. 1994)).

Frequently, authors following the PD perspective propose solutions that can be associated with the aim of correcting market failures in order to restore an efficient market, based on profit or utility maximization. However, very few of the reviewed studies adopted this approach as most examined contexts of reimbursement and administered prices, in which managed competition, rather than standard market competition, typically prevails. Several studies explicitly cited the work of Elinor Ostrom, searching for collective approaches to overcome the presumed dilemma structure (Beckmann and Pies 2016). Meanwhile, some proposed regulatory measures to restrict competition (Eussen et al. 2017).

\section{Evidence on Which the Proposed Solutions were Based}

Assessing the claim that a specific intervention should be pursued (e.g., that penalties should be raised to reduce the prevalence of doping in sports, which is due to a perceived dilemma) is a well-established topic of scientific investigation in the health science literature. A frequent assessment method is to analyze the level of evidence supporting the intervention's effectiveness. Generally, evidence from randomized experimental studies is considered much more credible than observational data. An assessment of the evidence should focus on study type, methodological limitations, and the endpoints used within the studies (Balshem et al. 2011; Guyatt et al. 2008).

For most of the described dilemmas, the level of evidence used to substantiate the claimed effectiveness of the proposed solution fell below what is considered "evidence" by proponents of evidence-based health policy at all: 56 of the dilemma descriptions were in essay-type articles based on theoretical considerations or opinions, illustrated using anecdotal evidence. Theoretical considerations were developed into mathematical models for six dilemmas (Creasy and Kinard 2013; Gkika et al. 2018; Glied 2001; Glied 2001; Goodman 1998; Kuga et al. 2019) and into model simulations for a further three dilemmas (Brouwer et al. 2008; Funk et al. 2010; Krauth et al. 1997). Nine dilemmas incorporated data from observational studies (Behrend et al. 2007; Bhattacharyya and Bauch 2012; Böhm et al. 2016; Brewer et al. 2017; Eber 2008; Glied 2001; Homann and Suchanek 2005; Liberati et al. 2009), which are categorized as the lowest level of evidence for evidence-based health policy. Only three dilemmas (Heckerling et al. 2006; Ives et al. 2018; Kolan 1996) drew upon experimental evidence. None of the studies substantiated their recommendations using a relevant randomized trial or systematic review of published evidence relating to the topic under investigation.

Figure 4 provides an overview of these results.

\section{Discussion}

The PD perspective conflates two claims: first, the normative claim that if ethical conflicts arise within the largely anonymous social production and distribution of goods and services, win-win solutions should be sought that everybody can consent to; and second, the positive claim that if these ethical conflicts arise, PDs can be identified that can be resolved by Pareto-improving institutions. Focusing on the second claim, this study identified empirical observations that are consistent with the PD perspective, but also demonstrated that, at least in medicine and public health, the connection between ethical conflicts and Pareto-improving solutions is much weaker than is suggested by the PD perspective.

\section{Results Confirming the Assumptions of the PD Perspective}

The 53 studies identified by this review-most of which discussed normative questions-provided 68 analyses of healthcare and public health topics based on PD structures. 
The PD thus clearly provides a relevant framework for business ethics in healthcare and public health. These results also suggest that analyzing incentives and the means to align individual incentives with socially desirable outcomes is a scientific activity that is relevant and rich in content.

The PD perspective assumes that, in modernity, the exchange of goods and services occurs within international, anonymous markets; frequently, authors following the PD perspective also appear to accept the premise that profit maximization in price-establishing markets is desirable and is the default mode of exchange in modern economies. A small minority of the dilemmas $(6 \%)$ occurred within the context of standard market competition; furthermore, at least some competitive elements could be identified in most of the dilemmas described. Therefore, competition and its effects appear to be a relevant topic of investigation within medicine and public health.

The PD perspective analyzes ethical conflicts from a public choice perspective, reducing actors' moral claims to the pursuit of self-interest and reframing moral problems as unintended collective self-damage. Most of the reviewed studies addressed ethical conflicts occurring at the macro level of healthcare and public health and involving unintended self-damage. Beyond an ethical approach, applying the $\mathrm{PD}$ perspective can be seen as a communication strategy for promoting institutional development, turning attention away from tradeoffs between ethical aims and self-interest, toward forgone win-win solutions (Pies 2009). Given the great importance of policy issues and complex institutions in healthcare (Thurner and Kotzian 2001), as well as the descriptions of unintended self-damage contained in the studies, the application of this approach in this field appears to be highly promising.

\section{Results Challenging the Assumptions of the PD Perspective}

The fact that dilemma structures were reported does not imply that the public choice perspective accounts for all relevant aspects of the problem under investigation. On the contrary, the empirical studies in this review typically identified other factors that are incorporated within social dilemma theory or concepts like the RANAS model; these are beyond the remit of purely rational individuals, as assumed by the PD perspective. Furthermore, individual preferences did not always appear to be rational, fixed, and exogenous to the analysis, as assumed in the homo oeconomicus model; instead, they were sometimes irrational, evolving, and resulting from cognitive biases, and were an important topic to include in the analysis (e.g., in the case of studies related to vaccination). None of the studies referring to the PD perspective incorporated empirical data-in fact, there was a disjuncture between the set of empirical studies and those applying the PD perspective. It might, therefore, be the case that methodological rigor in applying the PD perspective

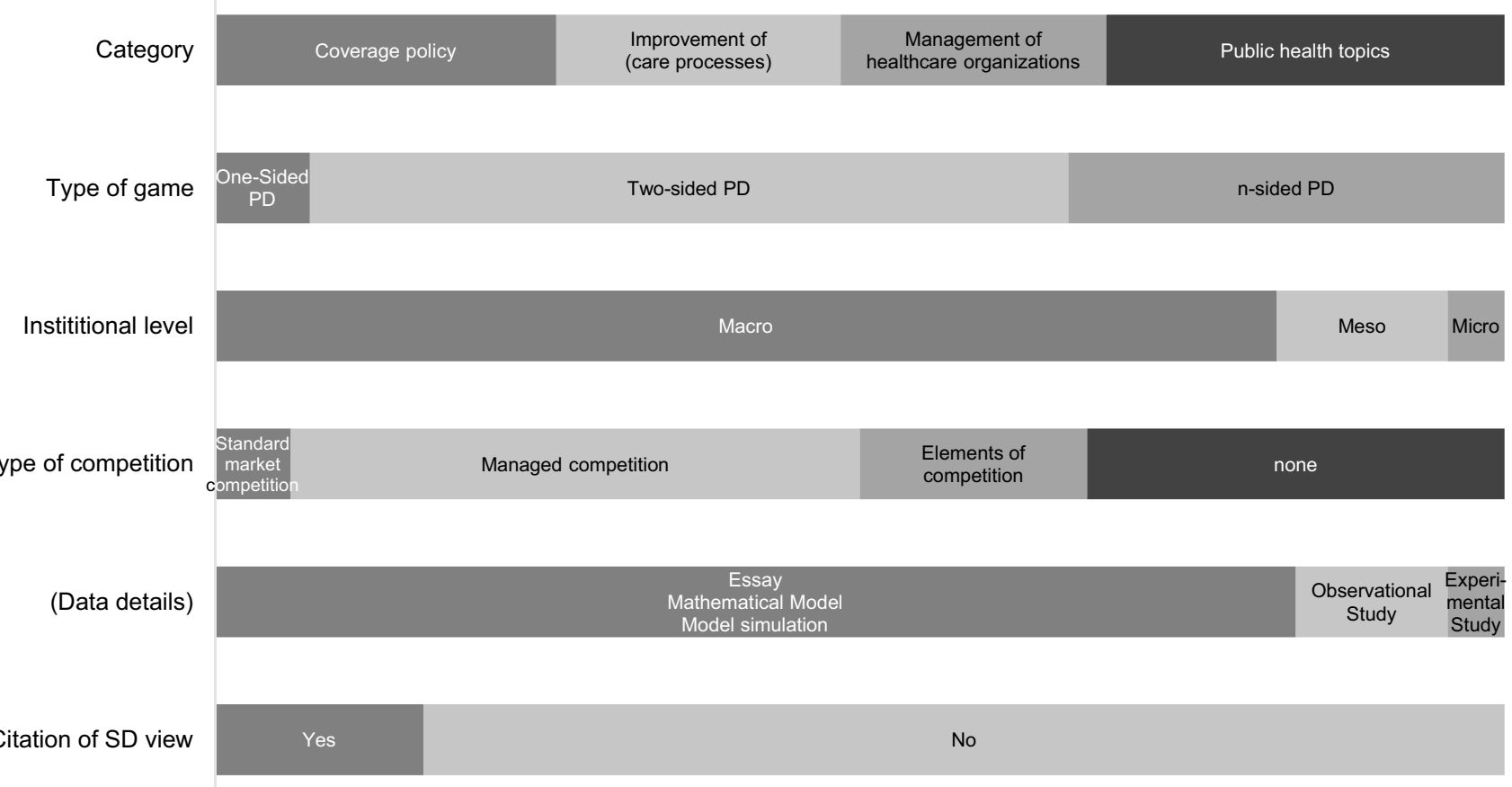

Fig. 4 Overview of the characteristics of investigated dilemma structures 
(i.e., restricting the analysis to incentives of rational individuals) blurs rather than sharpening the analysis.

The presumed condition of modernity that goods and services are exchanged within markets does not appear valid in healthcare. Only $6 \%$ of the described dilemmas occurred in the context of standard market competition, and market failure has been a core topic in the discipline of health economics since its inception in Arrow's seminal paper (Arrow 1963). In most cases where the described dilemma was associated with competition, the latter was highly restricted and largely determined by (normative) specifications established, for example, by social law or medical guidelines.

The PD perspective claims to be oriented toward practice, making recommendations on how to overcome moral problems in business exchange (Pies and Hielscher 2007). However, no attempt to verify this claim empirically could be identified. Most studies, including all those explicitly citing the PD perspective, were largely based on theoretical reasoning combined with selective statements about empirical observations. It is unclear whether the proposed remedies to moral problems have any positive effect. This is concerning because the methods of technology assessment and evidence-based health policy are well developed (Goodman 1998) and can also be applied to such questions as the optimal design of reimbursement schemes (Yuan et al. 2017). For instance, Yuan et al. (Sacconi 2007) showed that tying the level of reimbursement to evidence of quality (so-called "pay for performance") — an institution that could easily be proposed from an economic perspective-only appeared effective in restricted circumstances. The only randomized controlled trial referred to in the studies included interventions directed at factors typically excluded from a PD perspective, such as attitudes and norms. Interdisciplinary perspectives can be highly valuable in designing interventions to overcome PDs (Brewer et al. 2017). Even if a PD prevails, a variety of possible solutions could be derived and justified. Several PD descriptions and/or proposed institutions to overcome them lacked plausibility or detail. Both the claim to improve practice and specific proposals for achieving this need to be substantiated by empirical evidence.

\section{Implications for Applying the PD Perspective to Medicine and Public Health}

First, the PD perspective is not the only relevant framework for analyzing ethical conflicts in healthcare and public health. There is an abundance of bioethics and public health ethics literature that is relevant for business ethics but does not apply the PD perspective. One area of investigation is at the micro level of individual conflicts, rather than the macro level of conflicts subject to anonymous interactions and unintended negative effects. Attempts to apply the PD concept at the micro level of individual conflicts were frequently unconvincing. For example, in a study analyzing the conflict between a neurologist diagnosing brain death and parents hoping for their child's recovery, the apparent problem was different and mistaken evaluations of the outcomes of different strategies (ignoring the non-existence of the option for only one party to disconnect) (Riggs 2004). Before applying the PD perspective in healthcare, its relevance to addressing the topic in question needs to be justified. This corresponds with the assumption of Knoepffler et al. that the PD perspective complements, rather than substitutes for, other frameworks in medical ethics (Knoepffler and O'Malley 2016).

Second, there is a need for further evidence that the presumed dilemma structures do prevail and how exactly they can be characterized. The PD contains very specific characteristics (e.g., the one-shot game). The more detailed the analyses, the less obvious the dilemma structures appeared to be: in vaccination or doping, for example, aspects of how the payoffs are perceived and which types were included in the analysis had a substantial impact on the resulting game. Also, several authors stressed that repeated games, in which cooperation is a rational strategy, occur frequently in healthcare. Since proposals for resolution depend on the type of problem, application of the PD perspective should not only be justified theoretically but also substantiated with evidence about the structure of the target problem.

Third, while the PD perspective may help to identify possible solutions to ethical conflicts in medicine and public health, normative claims about which solution should be adopted by health policy-makers should also be empirically supported. Applying the PD perspective should not imply a general call for reform toward more market-based, profitoriented healthcare. Whether a specific type of (market) interaction is suitable for overcoming diagnosed moral problems under specific conditions is an empirical question, and given the abundant literature on market failure in healthcare (Zweifel et al. 2009), this should be the subject of thorough empirical investigation.

Finally, the approach's default assumption that healthcare and public health goods and services are exchanged within markets appears neither normatively neutral nor necessary for the approach to be relevant. Rather than presuming that "choices within rules" are "market choices," the results of this review suggest that, at least in healthcare, "choices within rules" should be seen as choices within the existing institutional setting, which may deliberately (and for established economic reasons) deviate from standard market interaction.

\section{Limitations of this Study}

This study was restricted to the investigation of evidence presented within manuscripts applying the dilemma view to healthcare. It was beyond the scope of this study to conduct 
original research on the presumed dilemma structures or complementary systematic searches for evidence on every institution the reviewed studies proposed. Therefore, it is likely that only part of the whole body of evidence for each institution is presented here. Data on the effectiveness of institutions may have been collected without explicitly referencing that the intervention is used to overcome a PD. Therefore, further research is necessary regarding specific ethical problems and proposed solutions to overcome them.

The categories used in this review to describe the different areas in which the PD perspective has been applied are not fully selective. For example, questions related to the overprovision of care could also be assigned to the categories of interaction among physicians or physician-patient interaction. Nevertheless, the categories were derived from a qualitative assessment of the different applications, and they usefully served to provide an overview of the studies and describe their variability. Moreover, the main ethical analysis was not affected by this limitation.

Due to a lack of established reporting schemes, some degree of fuzziness remained in the categories used to describe the studies. In particular, there was sometimes ambiguity regarding the level of interaction or type of competition. Although the numbers in each category reflect a qualitative assessment, rather than precise statistical estimates, this information was reported due to its relevance to the study's research topic.

The PD perspective can be criticized theoretically for various reasons. For example, with market failures widely acknowledged in the healthcare sector (Glied 2001), it is unclear whether a framework in which market competition plays an important role is relevant to this field. Also, the application of economic considerations to healthcare can be perceived as detrimental per se. Instead of such "economization," it has been claimed that concern for patients as vulnerable persons should be the core of ethical considerations in healthcare (Schnoor et al. 2017). Furthermore, the PD perspective has been subject to various theoretical debates between different schools of thought in business ethics, which may also contain aspects relevant to its application to healthcare. A review of this criticism was beyond the scope of this study.

Also, as the study focused on an empirical ethics investigation of the PD perspective's positive claims, a large number of theoretical questions regarding the PD perspective were beyond its scope. For example, it is unclear whether this approach should be considered non-consequentialist (given its focus on consent and generalizability of rules) or consequentialist (given its focus on maximizing utility). Further work should fully assess the suitability of this approach to healthcare.

\section{Implications for Further Research}

This study points toward different areas that warrant further research. Most importantly, empirical research is needed to assess the structure of conflicts in the provision of goods and services in medicine and public health, and whether proposed solutions are actually effective. Here, theories and methods of health services research, health technology assessment, and econometric analysis (e.g., Yuan et al. 2017; Lu et al. 2009) may provide valuable points of reference for further developing the PD perspective.

In addition, there is a need to expand the literature regarding possible solutions to dilemma structures beyond the concept of profit maximization within price-establishing markets, moving toward other concepts that better correspond with the healthcare context. Through valuable inspiration from social dilemma theory and Elinor Ostrom's work on collective approaches to managing common pooled resources, the PD perspective's theoretical ability to describe and resolve moral conflicts in healthcare may be enhanced (Ostrom 1990).

Consensual institutions need to be identified and agreed to by affected actors. It is unclear both theoretically and empirically how this can best be achieved in healthcare. The PD perspective may be advanced by integrating the theoretical and empirical literature on deliberation (e.g., Dolan et al. 1999) and by conducting further case studies in healthcare (e.g., Gansen et al. 2019) in order to develop new institutions that are substantiated by consent.

From an economic viewpoint, this study illustrated that theories based on individualist rational choice are not suitable for analyzing all economically relevant phenomena in the healthcare sector. Theoretical alternatives include extrawelfarist approaches to overcome the limitations of evaluations based on individual welfare and the Pareto efficiency criterion (Brouwer et al. 2008), or approaches following the institution economics tradition of integrating empirically richer concepts of human choice and interaction into the economic analysis of healthcare (Mooney et al. 2012; Mooney and Ryan 1993; Davis and McMaster 2015). There is a need to strengthen pluralism in (health) economics to increase its empirical validity and practical relevance.

Ethically, this study illustrated the need for guidance from other theories in cases where the PD perspective is not viable (alone). Though the call for identifying win-win situations can hardly be rejected, it may not be possible to identify a PD or a solution to which everybody can consent. Pies' framework of game, meta game, and meta-meta game suggests continuing social deliberation until the dilemma structure and institutions to overcome it are identified (Pies 2009). However, value conflicts that cannot be reconciled remain and policy decisions must be made. Here, guidance is needed from other sources like theories of medical and 
public health and business ethics, including from those that the PD perspective is intended to overcome.

One of these sources is the concept of medical ethos and the principles it implies. Turning back to the position statement by the Central Ethics Committee of the German Medical Association cited in the beginning of this manuscript (Bundesärztekammer 2013), a combination of both the concept of medical ethos and the PD view may be a promising approach. The position statement mentions a number of situations where considerations of business profitability may divert healthcare from good practice as required by medical ethos like, for example, unnecessary surgical procedures. The results of this review indicate that some of these situations may adequately be analyzed as PDs, and that new institutions may be identifiable which can align self-interest and medical ethos. Medical ethos may thus guide the search for still hidden PDs, and the PD view may guide the search for new institutions to overcome them. Rather than assuming that markets are suitable to improve the situation, a multitude of possible coordination mechanisms could be taken as a starting point for, first, searching institutions that can find consent; and second, consented institutions which are indeed effective in ameliorating the problems identified at the onset. Using such a revised PD view, homo oeconomicus is likely to obtain a comfortable and widely accepted place to sit in healthcare but s/he should wait to be seated by medical ethos and her colleagues from the department of evidence-based healthcare.

\section{Conclusions}

Given the large number of PD structures and potential means to overcome them reported in healthcare, the PD perspective seems to be relevant in this field. It appears, therefore, that thinking about ethical conflicts in terms of PDs and asking how existing incentive structures can be changed to promote win-win solutions are worthwhile endeavors for business ethics in healthcare.

However, this review illustrated that applying a rationalchoice-based framework for resolving moral problems involves the risk of ignoring aspects that are better described by empirically richer concepts such as the social dilemma theory. The claim of the PD perspective to provide viable solutions remains to be substantiated by evidence of such solutions' effectiveness. Furthermore, the PD perspective remains silent regarding moral problems that cannot be reframed as PDs, such as ethical dilemmas at the micro level of individual conflicts.

Applying the PD perspective to healthcare should thus be accompanied by both critical reflection on whether this framework is appropriate and empirical analysis of the supposed dilemma structures and the effectiveness of the proposed solutions to overcome them.

Acknowledgements The authors are grateful to Tom-Eric Grieme (TG), Henrik Hofmann (HH), Patrick Peltz (PP), and Alexander Zindler (AZ) for supporting the double independent study identification and full-text assessment and data extraction based on a predefined search. Also, we are indebted to Kirsten Jeude and Henning Manske from the literature search service EconBiz for providing the EconBiz data entries, to Julian Klinger for insightful comments and discussions at an earlier stage of this research project, and to two anonymous reviewers and the section editor for helpful comments and suggestions for improvement.

Funding Open Access funding enabled and organized by Projekt DEAL.

Open Access This article is licensed under a Creative Commons Attribution 4.0 International License, which permits use, sharing, adaptation, distribution and reproduction in any medium or format, as long as you give appropriate credit to the original author(s) and the source, provide a link to the Creative Commons licence, and indicate if changes were made. The images or other third party material in this article are included in the article's Creative Commons licence, unless indicated otherwise in a credit line to the material. If material is not included in the article's Creative Commons licence and your intended use is not permitted by statutory regulation or exceeds the permitted use, you will need to obtain permission directly from the copyright holder. To view a copy of this licence, visit http://creativecommons.org/licenses/by/4.0/.

\section{References}

Arrow, K. J. (1963). Uncertainty and the welfare economics of medical care. The American Economic Review, 53(5), 141-149.

Backhaus, J. G. (2005). The Elgar companion to law and economics (2nd ed.). Northampton, MA: Edward Elgar.

Balshem, H., Helfand, M., Schunemann, H. J., Oxman, A. D., Kunz, R., Brozek, J., et al. (2011). GRADE guidelines: 3. Rating the quality of evidence. Journal of Clinical Epidemiology, 64(4), 401-406.

Beckmann, M., Mackenbrock, T., Pies, I., Sardison, M., \& Ethik, W.-Z. F. G. (2004). Mentale Modelle und Vertrauensbildung -Eine wirtschaftsethische Analyse.

Beckmann, M., \& Pies, I. (2016). The constitution of responsibility: Toward an ordonomic framework for interpreting (corporate social) responsibility in different social settings. In C. Lutge \& N. Mukerji (Eds.), Order ethics: An ethical framework for the social market economy. Cham: Springer.

Behnke, L. M., Solis, A., Shulman, S. A., \& Skoufalos, A. (2013). A targeted approach to reducing overutilization: Use of percutaneous coronary intervention in stable coronary artery disease. Population Health Management, 16(3), 164-168. https://doi.org/10.1089/ pop.2012.0019.

Behrend, C., Felder, S., \& Busse, R. (2007). Susceptibility to strategy of the drug component of the IPHCC+RxGroups classification system in a risk-adjusted morbidity compensation scheme-A conceptional and data-supported analysis. Gesundheitswesen, 69(1), 1-10. https://doi.org/10.1055/s-2007-968171.

Benjamini, Y., \& Gafni, A. (1986). The diffusion of medical technology: A "prisoner's dilemma" trap? Socioeconomic Planning Sciences, 20(2), 69-74.

Bennett, C. L., Smith, T. J., George, S. L., Hillner, B. E., Fleishman, S., \& Niell, H. B. (1995). Free-riding and the prisoner's dilemma: 
Problems in funding economic analyses of phase III cancer clinical trials. Journal of Clinical Oncology, 13(9), 2457-2463. https ://doi.org/10.1200/jco.1995.13.9.2457.

Berndt, E. R., \& Trusheim, M. R. (2017). The information pharms race and competitive dynamics of precision medicine: Insights from game theory. NBER Working Papers: 24020. National Bureau of Economic Research, Inc.

Bernstein, J. (2000). Topics in medical economics: Lessons of the prisoner's dilemma. Journal of Bone and Joint Surgery of America, 82(4), 595-598.

Betsch, C. (2014). Overcoming healthcare workers vaccine refusalCompetition between egoism and altruism. Euro Surveillance, 19(48), 20979.

Bhattacharyya, S., \& Bauch, C. T. (2012). Mathematical models of the interplay between individual vaccinating decisions and disease dynamics: A need for closer integration of models and data. Human Vaccine and Immunotherapeutics, 8(6), 842-844. https:// doi.org/10.4161/hv.19616.

Böhm, R., Betsch, C., \& Korn, L. (2016). Selfish-rational non-Vaccination: Experimental evidence from an interactive vaccination game (Aufsatz in Zeitschrift, Article in journal). Journal of Economic Behavior and Organization, 131(2), 183-195.

Boos, L. (2002). Soziales Dilemma und die Organisation des Krankenhauses: die Aufgaben des Spitalmanagements. Muri: Muri/ Schweiz: SGGP.

Brennan, G., \& Buchanan, J. M. (1985). The reason of rules. Constitutional political economy. Cambridge, MA: Cambridge University Press.

Brewer, N. T., Chapman, G. B., Rothman, A. J., Leask, J., \& Kempe, A. (2017). Increasing vaccination: Putting psychological science into action. Psychological Science in the Public Interest, 18(3), 149-207.

Brouwer, W. B., Culyer, A. J., van Exel, N. J., \& Rutten, F. F. (2008). Welfarism vs. extra-welfarism. Journal of Health Economics, 27(2), 325-338. https://doi.org/10.1016/j.jhealeco.2007.07.003.

Buchanan, J. M. (1975). The limits of liberty: Between anarchy and Leviathan. Chicago [u.a.]: University of Chicago Press.

Bundesärztekammer, Z. E. B. D. (2013). Stellungnahme der Zentralen Kommission zur Wahrung ethischer Grundsätze in der Medizin und ihren Grenzgebieten (Zentrale Ethikkommission) bei der Bundesärztekammer: „Ärztliches Handeln zwischen Berufsethos und Ökonomisierung. Das Beispiel der Verträge mit leitenden Klinikärztinnen und -ärzten“. Deutsches Ärzteblatt, 110(30A), 1752-1756.

Bungenstock, J. M. (2011). Innovative Arzneimittel in der Gesetzlichen Krankenversicherung : eine normativ-ökonomische Analyse zu Versorgung und Finanzierung (1. Aufl. 2011 ed.): Baden-Baden: Nomos Verlag.

Chambers, D. W. (1995). The prisoner's dilemma-Should patients be sold? Journal of American College of Dentists, 62(4), 2-3.

Creasy, T., \& Kinard, J. (2013). Health care mergers and acquisitions: Implications of robbers cave realistic conflict theory and prisoner's dilemma game theory. Health Care Manager (Frederick), 32(1), 58-68. https://doi.org/10.1097/HCM.0b013e31827edadd.

Davis, J. B., \& McMaster, R. (2015). Situating care in mainstream health economics: An ethical dilemma? Journal of Institutional Economics, 11(4), 749-767.

de Vries, R., \& Gordijn, B. (2009). Empirical ethics and its alleged meta-ethical fallacies. Bioethics, 23(4), 193-201.

Djulbegovic, B., \& Hozo, I. (2012). When is it rational to participate in a clinical trial? A game theory approach incorporating trust, regret and guilt. BMC Medical Research Methodology, 12, 85. https:// doi.org/10.1186/1471-2288-12-85.
Djulbegovic, B., Hozo, I., \& Ioannidis, J. (2015). Modern health care as a game theory problem: Reply. European Journal of Clinical Investigation, 45(4), 443-443. https://doi.org/10.1111/eci.12414.

Dolan, P., Cookson, R., \& Ferguson, B. (1999). Effect of discussion and deliberation on the public's views of priority setting in health care: Focus group study. BMJ, 318(7188), 916-919.

Eber, N. (2008). The performance-enhancing drug game reconsidered: A fair play approach (Aufsatz in Zeitschrift, Article in journal). Journal of Sports Economics, 9(3), 318-327.

Ellingsen, G., \& Obstfelder, A. (2007). Collective expectationsIndividual action implementing electronic booking systems in Norwegian health care. International Journal of Medical Informatics, 76(Suppl 1), S104-S112. https://doi.org/10.1016/j.ijmed inf.2006.05.029.

Eussen, B. G. M., Schaveling, J., Dragt, M. J., \& Blomme, R. J. (2017). Stimulating collaboration between human and veterinary health care professionals. BMC Veterinary Research, 13(1), 174. https ://doi.org/10.1186/s12917-017-1072-x.

Feng, X., Wu, B., \& Wang, L. (2018). Voluntary vaccination dilemma with evolving psychological perceptions. Journal of Theoretical Biology, 439, 65-75. https://doi.org/10.1016/j.jtbi.2017.11.011.

Francis, C. K. (2001). Medical ethos and social responsibility in clinical medicine. Journal of Urban Health, 78(1), 29-45. https://doi. org/10.1093/jurban/78.1.29.

Funk, S., Gilad, E., \& Jansen, V. A. (2010). Endemic disease, awareness, and local behavioural response. Journal of Theoretical Biology, 264(2), 501-509.

Gansen, F., Klinger, J., \& Rogowski, W. (2019). MCDA-based deliberation to value health states: Lessons learned from a pilot study. Health and Quality of Life Outcomes, 17(1), 112.

Gkika, D. A., Magafas, L., Cool, P., \& Braet, J. (2018). Balancing nanotoxicity and returns in health applications: The Prisoner's Dilemma. Toxicology, 393, 83-89. https://doi.org/10.1016/j. tox.2017.11.008.

Glied, S. A. (2001). Health insurance and market failure since Arrow. Journal of Health Politics, Policy and Law, 26(5), 957-965.

Goodman, C. S. (1998). Healthcare technology assessment: Methods, framework, and role in policy making. American Journal of Managed Care, 4 Spec No, SP200-214; quiz SP215-206.

Guyatt, G. H., Oxman, A. D., Vist, G. E., Kunz, R., Falck-Ytter, Y., Alonso-Coello, P., et al. (2008). GRADE: An emerging consensus on rating quality of evidence and strength of recommendations. BMJ, 336(7650), 924-926.

Haugen, K. K. (2004). The performance-enhancing drug game. Journal of Sports Economics, 5(1), 67-86. https://jse.sagepub.com/ content/by/year.

Heckerling, P. S., Gerber, B. S., \& Weiner, S. J. (2006). The "resident's dilemma"? Values and strategies of medical residents for education interactions: A cellular automata simulation. Methods of Information in Medicine, 45(4), 455-461.

Homann, K., \& Pies, I. (1994). Wirtschaflsethik in der Moderne: Zur okonomischen Theorie der Moral. In R. Greshoff \& W. Loh (Eds.), Ethik und Sozialwissenschaften : EuS : Streitforum für Erwägungskultur (Vol. 5, pp. 3-12). Stuttgart: Lucius and Lucius.

Homann, K., \& Suchanek, A. (2000). Ökonomik eine Einführung (Neue ökonomische Grundrisse). Tübingen: Mohr Siebeck.

Homann, K., \& Suchanek, A. (2005). Ökonomik eine Einführung (2., überarb. Aufl. ed., Neue ökonomische Grundrisse).

Ives, J., Dunn, M., Molewijk, B., Schildmann, J., Baeroe, K., Frith, L., et al. (2018). Standards of practice in empirical bioethics research: Towards a consensus. BMC Medical Ethics, 19(1), 68.

Jadlow, J. M. (1978). Hospital Competition and the 'Prisoner's Dilemma'. Rivista Internazionale di Scienze Economiche e Commerciali, 25(4), 360-369. 
Janssens, W., \& Kramer, B. (2016). The social dilemma of microinsurance: Free-riding in a framed field experiment. Journal of Economic Behavior and Organization, 131, 47-61. https://www. sciencedirect.com/science/journal/01672681.

Kettner, M. (2017). Stärken und Schwächen ordonomischer Überbietungsargumente : Kommentar zum Hauptbeitrag von Ingo Pies (Aufsatz in Zeitschriften, Article in journal). Zeitschrift für Wirtschafts- und Unternehmensethik, 18(2), 253-258. https://doi. org/10.5771/1439-880x-2017-2-253.

Knoepffler, N., \& O'Malley, M. (2016). An ordonomic perspective in medical ethics. In C. Lutge \& N. Mukerji (Eds.), Order ethics: An ethical framework for the social market economy. Cham: Springer.

Kolan, I. (1996). Normative Wirtschaftswissenschaft : theoretische Fundierung und praktische Anwendung am Beispiel der Gesundheitspolitik (1. Auflage ed.). Sinzheim: Pro Universitate Verlag.

Krauth, C., Schwartz, F. W., Perleth, M., Buser, K., Busse, R., \& von der Schulenburg, J.-M. (1997). Zur Weiterentwicklung des Vergütungssystems in der ambulanten ärztlichen Versorgung. Hannover: Forschungsstelle Gesundheitsökonomie und Gesundheitssystemforschung.

Kuga, K., Tanimoto, J., \& Jusup, M. (2019). To vaccinate or not to vaccinate: A comprehensive study of vaccination-subsidizing policies with multi-agent simulations and mean-field modeling. Journal of Theoretical Biology, 469, 107-126. https://doi.org/10.1016/j. jtbi.2019.02.013.

Liberati, A., Altman, D. G., Tetzlaff, J., Mulrow, C., Gotzsche, P. C., Ioannidis, J. P., et al. (2009). The PRISMA statement for reporting systematic reviews and meta-analyses of studies that evaluate healthcare interventions: Explanation and elaboration. BMJ, 339, b2700.

Lu, C., Frank, R. G., \& McGuire, T. G. (2009). Demand response to cost sharing under managed health care. Contemporary Economic Policy, 27(1), 1-15.

Lutge, C. (2005). Economic ethics, business ethics and the idea of mutual advantages. Business Ethics: A European Review, 14(2), $108-118$

Lütge, C., Armbruster, T., \& Muller, J. (2016). Order ethics: Bridging the gap between contractarianism and business ethics. Journal of Business Ethics, 136(4), 687-697. https://doi.org/10.1007/s1055 1-015-2977-6.

Lütge, C., \& Mukerji, N. (2016). Order ethics an ethical framework for the social market economy. Cham: Springer.

Martino, M. G. (2018). Civil economy: An alternative to the social market economy? Analysis in the framework of individual versus institutional ethics. Journal of Business Ethics. https://doi. org/10.1007/s10551-018-4069-x.

Moher, D., Liberati, A., Tetzlaff, J., \& Altman, D. G. (2009). Preferred reporting items for systematic reviews and meta-analyses: The PRISMA statement. BMJ, 339, b2535.

Mooney, G., \& Ryan, M. (1993). Agency in health care: Getting beyond first principles. Journal of Health Economics, 12(2), $125-135$.
Mooney, G., Tinghög, G., \& Kalkan, A. (2012). The need for a new paradigm in Scandinavian health economics. Nordic Journal of Health Economics, 1(2), 119-133.

Peterson, M. (Ed.). (2015). The prisoner's dilemma (Classic philosophical arguments). Cambridge, MA: Cambridge University Press.

Pies, I. (2009). Das ordonomische Forschungsprogramm. Diskussionspapier des Lehrstuhls für Wirtschaftsethik an der Martin-LutherUniversität Halle-Wittenberg 2009, 7. Halle: Martin-Luther-Univ. Halle-Wittenberg.

Pies, I. (2011). Wie kommt die Normativität ins Spiel? - Eine ordonomische Argumentationsskizze.

Pies, I. (2017). Ordonomik als Methode zur Generierung von Überbietungsargumenten : eine Illustration anhand der Flüchtlings(politik) debatte (Aufsatz in Zeitschriften, Article in journal). Zeitschrift für Wirtschafts- und Unternehmensethik, 18(2), 171-200. https:// doi.org/10.5771/1439-880x-2017-2-171.

Pies, I., \& Hielscher, S. (2007). Das Problem weltmarktlicher Arzneimittelversorgung: ein Vergleich alternativer Argumentationsstrategien für eine globale Ethik. Halle, Saale: Martin-LutherUniversität Halle-Wittenberg, Lehrstuhl für Wirtschaftsethik.

Pies, I., \& Homann, K. (2008). Freiheit durch Demokratie Festschrift für Karl Homann (Ökonomik und Ethik, Vol. 3). Berlin: wvb.

Pies, I., \& Sardison, M. (2006). Wirtschaftsethik. In N. Knoepffler, P. Kunzmann, I. Pies \& A. Siegetsleitner (Eds.), Einführung in die Angewandte Ethik (Orig.-Ausg. ed., Vol. 1, pp. 267-298). Freiburg [u.a.]: Alber.

Riggs, J. E. (2004). Medical ethics, logic traps, and game theory: An illustrative tale of brain death. Journal of Medical Ethics, 30(4), $359-361$.

Rogowski, W. H. (2018). Evaluation as institution: A contractarian argument for needs-based economic evaluation. BMC Medical Ethics, 19(1), 59.

Sacconi, L. (2006). A social contract account for CSR as an extended model of corporate governance (I): Rational bargaining and justification. Journal of Business Ethics, 68(3), 259-281.

Sacconi, L. (2007). A social contract account for CSR as an extended model of corporate governance (II): Compliance, reputation and reciprocity. Journal of Business Ethics, 75(1), 77-96.

Schnoor, J., Braehler, E., Ghanem, M., \& Heyde, C. E. (2017). The impact of economic rationalization, prioritization and rationing on job satisfaction, motivation and team cohesion in hospitals: A survey among retired physician executives in Germany. Patient Safety in Surgery, 11, 3.

Yuan, B., He, L., Meng, Q., \& Jia, L. (2017). Payment methods for outpatient care facilities. Cochrane Database of Systematic Reviews, 3, CD011153.

Zweifel, P., Breyer, F. H. J., \& Kifmann, M. (2009). Health economics (2. Aufl. ed.). Berlin: Springer.

Publisher's Note Springer Nature remains neutral with regard to jurisdictional claims in published maps and institutional affiliations. 